\title{
Primeiros estudos funcionalistas sobre a repetição na oralidade no Corpus Português Culto de Vitória da Conquista
}

\author{
Lorenna Oliveira dos Santos \\ Universidade Estadual do Sudoeste da Bahia (UESB), Vitória da Conquista, Bahia, Brasil \\ loreoliveira@live.com
}

\section{DOI: $\underline{\text { http://dx.doi.org/10.21165/el.v45i1.665 }}$}

\begin{abstract}
Resumo
Neste artigo ${ }^{1}$, estudaremos um fenômeno linguístico frequentemente utilizado na oralidade, a repetição. Para tal estudo, basear-nos-emos, principalmente, nos estudos Funcionalistas propostos por Castilho (1994), Givón (1995) e Oliveira (1998), com o objetivo de caracterizar as estruturas repetidas, identificando-as quanto à forma e à função e demonstrando como elas são regidas pelos princípios de iconicidade e de marcação expressiva. Para tanto, retiraremos, do Corpus Português Culto de Vitória da Conquista, ocorrências de elementos lexicais, sintagmáticos e oracionais e os classificaremos segundo os seguintes aspectos funcionais: a enumeração, a paralelização e o reforço.
\end{abstract}

Palavras-chave: Funcionalismo; oralidade; repetição.

First Functionalist Studies about Repetition in Oral Communication in the Vitória da Conquista Corpus of Formal Portuguese

\begin{abstract}
This article studies a phenomenon often found in oral communication, namely repetition. Based on Functionalism and on studies carried out by Castilho (1996), Givón (1995) and Oliveira (1998), the forms and functions of repeated structures are characterized in order to evidence how they are governed by the principles of iconicity and expressive markedness. For this reason, occurrences of lexical, syntagmatic and clausal elements are extracted from the Vitória da Conquista Corpus of Formal Portuguese and are classified according to the following functional aspects: enumeration, parallelization and reinforcement.
\end{abstract}

Keywords: Functionalism; oral communication; repetition.

\section{Introdução}

A repetição é um fenômeno linguístico que tem sido estudado por meio de diversas estratégias, como, por exemplo, a retomada, a paráfrase e o paralelismo. Além disso, pesquisadores têm observado a descrição e a função desse fenômeno, principalmente na conversação, na qual é utilizado frequentemente. Observamos que, diante das situações de maior monitoramento, o falante procura evitar a repetição, tendo em vista que, ao seu uso, ainda é associado, na sociedade, muitas vezes, um valor negativo, já que, tradicionalmente, esse fenômeno é avaliado, em um texto, como algo redundante, pouco estruturado e desnecessário.

\footnotetext{
${ }^{1}$ Este artigo foi produzido sob orientação da Professora Doutora Valéria Viana Sousa-UESB/PPGLin.
} 
Em um estudo feito por Silva (2008), no âmbito da escrita, ao contrário desse juízo de valor mencionado, o mecanismo da repetição foi conveniente e adequado para ser utilizado em gêneros textuais como o artigo de opinião, visto que a exposição de ideias era o alvo principal. Assim, a reiteração de um mesmo termo exerce uma função coesiva, facilitando a compreensão do texto. Em nossa pesquisa, também, contrariando o senso comum, consideramos a repetição como um recurso positivo, especialmente na construção do texto falado, uma vez que o falante utiliza tal recurso objetivando um maior entendimento e uma maior conexão do discurso. Desse modo, partindo dessas observações e recordando Marcuschi (2006), argumentamos, no presente trabalho, que, na repetição, o informante exerce diversas funções na fala as quais auxiliam na "organização discursiva e na monitoração da coerência textual; [favorecem] a coesão e a geração de sequências mais compreensíveis; [dão] continuidade à organização tópica e [contribuem] nas atividades interativas." (MARCUSCHI, 2006, p. 219).

Oliveira (1998) propõe dividir a repetição, que ocorre na modalidade oral, em funções mediais de microestruturação, referentes à estruturação interna de unidades discursivas (UDs) ${ }^{2}$ e em funções mediais de interestruturação, referentes à organização de UDs entre si. A microestruturação divide-se em dez modalidades funcionais articuladoras internas de unidade discursiva (microestruturação), que são: paralelização; reforço; contraste; desdobramento; temporalização; reparação; enumeração; reordenação; tematização e confirmação. Por outro lado, a interestruturação categorizase em oito processos funcionais na articulação de UDs entre si, que são: amplificação; endosso; focalização; distinção; atualização; balizamentos; difusão e reintrodução.

Tomando como referência essa categorização da repetição, versaremos, neste estudo, sobre três aspectos funcionais da repetição na oralidade: a enumeração, a paralelização e o reforço, baseando-nos nos Estudos Funcionalistas que, pautados em Givón (1995), têm como princípio básico a análise da expressividade de uma determinada língua, observando as suas estruturas linguísticas em situações comunicativas. Para tal estudo, propomos a discussão sobre i) a forma como os falantes do Português Culto de Vitória da Conquista (Corpus PCVC) utilizam o recurso da repetição em suas falas; ii) a importância desse uso na interação verbal; iii) os aspectos funcionais através dos quais são organizadas cognitivamente, por meio do fenômeno da repetição, as estruturas gramaticais produzidas pelos falantes do Corpus PCVC; e ainda, iv) qual dos aspectos funcionais selecionados - enumeração, paralelização e reforço - é mais produtivo na amostra estudada.

Supondo que as repetições sejam "peças-chave" necessárias ao processamento textual-discursivo e à comunicação entre os interlocutores, hipotetizamos a priori que: i) o recurso é altamente produtivo na oralidade; ii) a interação dos interlocutores na fala é facilitada por esse mecanismo; iii) o sistema de repetição é motivado cognitivamente, refletindo o modo como o indivíduo interpreta a realidade que está a sua volta; e, por fim, iv) dos aspectos funcionais selecionados, o reforço é o mais produtivo nos dados analisados no Corpus.

Então, pela diversidade de características da repetição e pela importância que esse recurso tem na oralidade, neste trabalho consideramos que as repetições podem manifestar-se de diversas formas e que são multifuncionais e, para estabelecer esse

\footnotetext{
2 Segundo Rios de Oliveira (1998), a unidade discursiva é composta por dois elementos mínimos: orações, com verbo expresso, e/ou frases, com verbo elidido.
} 
diálogo, primeiramente, no aporte teórico, abordaremos, em linhas gerais, o Funcionalismo e como tal teoria nos auxilia no estudo da repetição na oralidade; depois, apresentaremos como o Corpus analisado foi construído; após essa seção, na análise e discussão dos dados, estabeleceremos a relação dos dados com a teoria adotada; e, para finalizar, faremos nossas considerações finais.

\section{Aporte teórico: o Funcionalismo}

O Funcionalismo ${ }^{3}$ é visto como um movimento derivado do Estruturalismo que teve origem no Círculo Linguístico de Praga, em 1926, tendo como principais precursores Jakobson, Trubetzkoy, Martinet e Mathesius. Tal movimento é caracterizado pelo fundamento de que a estrutura fonológica, gramatical e semântica das línguas é definida pelas funções que exercem nas situações comunicativas, isto é, o princípio de iconicidade ${ }^{4}$. Logo, se alguma estrutura linguística é utilizada frequentemente, é devido a alguma função. Nas palavras de Tavares (2003, p. 57), a iconicidade

[...] não implica, porém, a existência de correspondências biunívocas e não arbitrárias [...]. Formas e funções estão sempre em mobilidade, havendo geralmente mais de uma forma para cada função e mais de uma função para cada forma. A iconicidade que caracteriza a língua reside no fato de que as formas são usadas sob influência de um conjunto de motivações funcionais.

Para entendermos melhor o princípio da iconicidade, consideramos necessário recorrer ao conceito de língua no Funcionalismo. De acordo com Areas e Martelotta (2003), a língua, no polo funcionalista, é caracterizada como um instrumento de comunicação, tendo em vista a maleabilidade da estrutura, que está sujeita a pressões advindas de diferentes situações pragmático-discursivas, que ajudam a compor a estrutura gramatical. Nesse sentido, o discurso gera o sistema linguístico e, este, por sua vez, é maleável e está em constante transformação. Assim, ao contextualizar as ocorrências gramaticais que foram geradas no discurso, "a gramática funcional toma como ponto de partida as significações das expressões linguísticas, indagando como elas se codificam gramaticalmente." (CASTILHO, 1994, p. 76). Portanto, no Funcionalismo, a língua é analisada do ponto de vista social, isto é, dando relevância ao contexto social, pois defende-se que o falante emprega a língua, adequadamente, nas diversas situações comunicativas.

Ao estudar a língua, os funcionalistas orientam-se por meio da noção pancrônica de mudança, pois são observadas as relações cognitivas e comunicativas que se desenvolvem no indivíduo em um determinado contexto e que se manifestam de maneira universal, "já que refletem os poderes e as limitações da mente humana para armazenar e transmitir informações” (AREAS; MARTELOTTA, 2003, p. 28).

Em suma, segundo Lima-Hernandes (2011), a análise do sistema linguístico, no Funcionalismo, parte do falante, considerando não só o usuário da língua, mas, também,

\footnotetext{
${ }^{3}$ Ver Neves (1997).

${ }^{4}$ De acordo com Tavares (2003), a noção de iconicidade pode ser localizada já nos escritos de Aristóteles, porém, o filósofo grego considera que a linguagem traduz o pensamento e este, por sua vez, traduz a realidade.
} 
toda a situação comunicativa, tendo em vista que "a motivação e os objetivos para a interação verbal são questões centrais" (LIMA-HERNANDES, 2011, p. 21), isto é, para os funcionalistas, a sintaxe e a semântica devem ser estudadas através da pragmática, analisando a descrição de expressões, dentro das condições de uso, que revelam a competência comunicativa do indivíduo, para, então, entender o funcionamento da estrutura gramatical.

Realizada essa primeira ancoragem teórica, na próxima subseção, retrataremos o nosso objeto de estudo fundamentado no Funcionalismo.

\subsection{A Repetição na oralidade à luz do Funcionalis mo}

De acordo com Silva (2008), pesquisas recentes, tanto da Linguística Funcional, compreendendo a continuidade de referência, quanto da Linguística Textual, compreendendo o processo de referenciação ${ }^{5}$, a repetição tem sido abordada como um mecanismo bastante relevante de retomada de um referente do discurso. No presente artigo, por opção metodológica, faremos uma abordagem baseada, somente, na Linguística Funcional.

Para Givón (1983), a repetição é uma estratégia que faz parte do princípio de continuidade tópica/referencial, isto é, a forma de expressão de um determinado referente no discurso está associada ao maior ou menor grau de predizibilidade desse referente naquela posição do discurso, sendo que essa expressividade pode ocorrer entre nomes, modificadores ou não, através de pronomes, fortes ou fracos, e, também, por anáfora zero. Em um estudo mais recente, Oliveira (1998) define a repetição como a "correferência, exata ou reparada, de um termo lexical no fluxo textual, termo este tomado isoladamente ou na composição de sintagmas nominais e verbais" (OLIVEIRA, 1996, p. 147).

Ainda de acordo com Oliveira (1996), a repetição é um método de produção e de amplificação semântica e sintática e, além disso, um processo gramatical regular. Nessa perspectiva, considerando que cada forma da língua é detentora de um significado e que múltiplos significados se manifestam por formatação diversificada, a repetição exerce um papel multidirecional: "é anáfora formal, enquanto recuperação de termo(s) já ocorrido(s), e catáfora conceptual, pela nova função elaborada" (OLIVEIRA, 1996, p. 150).

Partindo da orientação teórica de que o sistema de repetição compõe o processo de organização da experiência humana, desenvolvendo, cognitivamente, um diálogo temático, explicaremos o aspecto funcional da repetição fundamentado em um princípio cognitivo. De acordo com Dubois e Votre (1994), na língua, considerando o seu caráter mental e conceptual, é expressada, também, materialmente uma semelhança com a maneira como o ser humano abstrai a realidade que está a sua volta. A experiência integra os processos de regularização lógica e pode se materializar operando na estruturação das diversas camadas discursivas.

Dessa maneira, com o modelo cognitivo que adotamos, temos o objetivo de encontrar, nas expressões da língua, a influência de fatores externos, pois a interpretação do discurso está associada diretamente com o modo de interpretação de mundo do indivíduo, visto que, como dissemos anteriormente, nas palavras de Lima-

\footnotetext{
${ }^{5}$ Conferir Marcuschi (2002).
} 
Hernandes (2011), o estudo do sistema linguístico, na gramática funcional, parte do falante, dando relevância não só ao fato de ele ser usuário da língua, como, também, ao contexto e à motivação que conduzem, cognitivamente, a sua interação verbal naquele determinado momento, com aquele determinando interlocutor.

Em suma:

A opção pelo tratamento funcional de base cognitiva parte do entendimento da gramática como unidade complexa e multifuncional, estruturada componencialmente por procedimentos, de certa forma, estáveis. Os mecanismos de repetição, enquanto integrantes dessa entidade linguística, consideram-se, assim, constituintes regulares do diálogo temático, estruturas funcionais de representação, motivadas cognitivamente. A experiência funda e a interação organiza, numa relação em que o papel funcional orienta a forma representacional (OLIVEIRA, 1998, p. 37).

No tratamento funcional da repetição no modelo conversacional, consideramos dois princípios que são de grande valia dada sua produtividade: a iconicidade e a expressividade.

A iconicidade, conforme abordamos na seção anterior, corresponde "à relação motivada de um-para-um entre o conteúdo e sua representação" (OLIVEIRA, 1998, p. 40). O princípio de iconicidade, ainda, pode ser estudado segundo três subprincípios, a saber: o da quantidade (os subtópicos mais expressivos são marcados por um grande número de unidades discursivas, geralmente, de forma parafrástica); proximidade (as unidades discursivas que partilham de assuntos semelhantes tendem a ficar mais próximas na sequência conversacional); e o da ordenação linear dos segmentos (gradação de sentido produzida pelo fluxo de unidades discursivas, constituídas de subtópicos conversacionais).

A respeito do outro preceito funcionalista, a expressividade, Dubois e Votre (1994) apresentam o princípio da marcação expressiva em função do princípio de marcação "na tentativa de explicitação da multidirecionalidade da relação entre forma e função discursiva” (OLIVEIRA, 1998, p. 42).

As expressões "marcado" e "não marcado" foram originadas pela Escola de Praga. De acordo com Cunha (2015), geralmente, o principal objetivo desse preceito é o contraste entre dois elementos de uma determinada categoria linguística que pode ser fonológica, morfológica ou sintática. O elemento marcado é o que possui uma característica ausente em relação ao elemento considerado não marcado. As formas não marcadas têm algumas características, tais como: (i) maior frequência de ocorrência; (ii) contexto de ocorrência diversificado; (iii) forma simples e (iv) aquisição prematura pelas crianças. A forma marcada, por sua vez, com características opostas às elencadas, são escolhidas pelo falante, no ato discursivo, em busca de uma maior expressividade.

Portanto, pelo fato de a marcação por si mesma não conseguir explicar as várias estratégias encontradas na modalidade da fala em sua expressão, ocorre a relação marcação-expressividade, pois, alguns processos são justificados pelo princípio de marcação, já outros são justificados pelo de expressividade. Assim, na junção desses dois elementos, há elementos mais consolidados para uma melhor análise do fenômeno linguístico. 
Como dissemos anteriormente, para este estudo, realizamos um recorte, no qual escolhemos três aspectos funcionais da microestruturação, postulados por Oliveira (1998), a saber: a enumeração, definida quando há a repetição de dois ou mais termos que estão dispostos de forma adjacente e que contêm diferentes sentidos, mas estruturas semelhantes ou análogas; a paralelização, que ocorre quando o falante retoma uma declaração anterior de repetições lexicais e de uma organização sintática análoga que foi dita por ele mesmo ou por outro locutor, com ou sem variação formal; e o reforço, quando o falante, em uma autorrepetição (repetição de elementos que foram ditos anteriormente pelo próprio falante) ou em uma heterorrepetição (repetição de elementos que foram ditos por outro locutor), repete formas lexicais ou sintagmáticas sem variação, caracterizando, assim, um processo de expansão, ou seja, uma estratégia que acata o princípio de iconicidade, no qual um conjunto de linguagem idêntica, em posição idêntica, adequa-se a um volume informacional.

A seguir, apresentaremos o Corpus e a análise de construções presentes no Corpus PCVC que envolvem o fenômeno da repetição, objeto de estudo desta pesquisa, identificando-as quanto à forma e à função, além de quantificar as ocorrências de cada aspecto funcional.

\section{O Corpus analisado}

O Corpus Português Culto de Vitória da Conquista, constituído pelo Grupo de Pesquisa em Linguística Histórica e pelo Grupo de Pesquisa em Sociofuncionalismo CNPq, está pautado na escolha daquela parcela da população que tem, no mínimo, onze (11) anos de escolaridade. A metodologia utilizada para a obtenção do Corpus foi orientada por trabalhos sociolinguísticos que se fundamentam na perspectiva variacionista laboviana e a técnica de amostra confeccionada para as entrevistas foi realizada a partir da divisão da BR116, característica peculiar e relevante na cidade. Além disso, como requisito para a composição do Corpus, todos os informantes devem ser naturais do município. Assim, doze (12) informantes de cada Corpus foram selecionados no lado oeste e doze (12) do lado leste da cidade de Vitória da Conquista. No entanto, para este trabalho, fizemos um recorte e escolhemos, para compor a nossa amostra de análise, seis (06) entrevistas, estratificadas em sexo (masculino e feminino) e em faixas etárias I (15 a 25 anos), II (26 a 50 anos) e III (acima de 50 anos). Contudo, essas estratificações não foram relacionadas às ocorrências no recorte da pesquisa, foram realizadas apenas como uma representação do Corpus PCVC.

Portanto, pautados nos princípios de iconicidade e de expressividade do Funcionalismo, propostos por Givón (1995) e Oliveira (1998), investigamos ocorrências que apresentam o fenômeno da repetição no Corpus PCVC, identificando-as quanto à forma e à função ${ }^{6}$.

\footnotetext{
${ }^{6} \mathrm{O}$ objetivo maior da análise é a fala do informante. Contudo, nesse tipo de análise se faz necessária a observação da fala do entrevistador, que, nesse Corpus, caracteriza-se como alguém também pertencente ao Português Culto.
} 


\section{A análise}

Todas as ocorrências submetidas à análise foram extraídas do Corpus Português Culto de Vitória da Conquista e, depois, foram quantificadas a fim de identificar o aspecto funcional que seja mais produtivo entre os três aspectos selecionados, conforme mencionamos anteriormente.

Quanto a alguns aspectos formais da enumeração, podemos afirmar que, nessa estratégia, geralmente, não há variação e ocorre em uma autorrepetição. Em nossa amostra de estudo, foram encontradas $29 \%$ de repetições enumeradoras. Marcuschi (2006) classifica tal função como listagem, pois o falante gera listas que nos permitem identificá-las como paralelismos sintáticos, frequentemente com variações lexicais e morfológicas e manutenção de uma formação nuclear. Vejamos os exemplos de (01) a (03):

(01) INF: eu vou pra Vitória,

$\{\varnothing\}$ Espírito Santo,

$\{\varnothing \quad\}$ eh Salvadô (A.S.A, PCVC);

(02) INF: [...] e eles chegavam na sala de aula com cheiro de... de cebola, de fêjão que tinha comido, certo?, então... chêro de gente... de gente que trabalha e que chega à noite [...] (A.I.R.M, PCVC);

(03) INF: Morei em Brumado, morei em Cachoeira do São Félix [...], morei em uma fazenda perto do município Firmino Alves, morei em Sobral no Ceará e morei aqui em Vitória da Conquista (F.S.L.B, PCVC);

Podemos observar que o primeiro informante não repete o termo vou, mas inferimos o referido termo, já que a lista de cidades foi gerada através de uma repetição matriz. Em outras palavras, houve, nos enunciados, a presença de um suporte que fez os preenchimentos dos vazios que, posteriormente, foram gerados; o segundo informante, também, elenca uma série de cheiros, partindo de um enunciado matriz eles chegavam na sala de aula com cheiro de; por fim, no terceiro, podemos observar, claramente, a motivação icônica, manifestada no (i) subprincípio da quantidade, pois o informante repete cinco vezes a expressão morei, enumerando sempre um lugar diferente e no (ii) subprincípio da proximidade, uma vez que a maneira contígua com que esse termo se organiza, revela um destaque na sua significação. Além disso, na repetição de morei a cada novo enunciado, tal forma verbal é reiterada (anáfora) em função da lista de cidades nas quais o informante residiu. Ainda em (03), ao invés de o falante realizar o verbo inicialmente e elidi-lo depois, como orientam as regras da modalidade escrita, ele opta pelo processo da repetição, como uma forma de intensificar a quantidade de cidades nas quais morou.

Em relação à paralelização, também, foram encontradas $29 \%$ de ocorrências desse aspecto funcional. Apesar de a paralelização também ter uma relação bem marcada com o paralelismo sintático, citado por Marcuschi (2006), essa categoria diferencia-se da enumeração, pois não revela uma significação distintiva visivelmente entre seus integrantes. $\mathrm{O}$ falante somente reitera um enunciado anterior que foi dito por ele mesmo ou por outro locutor, com ou sem variação formal. Marcuschi (2006) nomeia esse tipo de repetição como amálgamas sintáticos, pois, neste caso, as repetições funcionam como recursos sequenciais da coesão que trabalham na produção textual em 
um jogo de construção-reconstrução, aproveitando-se de segmentos anteriores para repeti-los. Vejamos os fragmentos de (04) a (06):

(04) DOC: 'Cê gosta de dá aula de inglês, F.? INF: Eu gosto de dá aula de inglês porque eu mantenho contato com a língua inglesa (F.S.L.B, PCVC);

DOC: $\mathrm{O}$ que você acha da educação em Conquista? INF: Olha a cida... a educação em Conquista ela tá um pôco deixando a desejar, né [...] (C.B.S, PCVC);

(06) DOC: Você concorda com a ideia de que Conquista é uma cidade que tem muitas opções? INF: Não, não tem. Não tem muitas opções. (A.S.A, PCVC);

O informante retoma, em sua resposta, as ocorrências ditas pelo documentador, obedecendo ao subprincípio de proximidade, pois as unidades discursivas repetidas estão próximas e compartilham o mesmo assunto. No exemplo (04), o informante fornece uma explicação (catáfora), reiterando a construção do documentador (anáfora); em (05) e em (06), os informantes expressam uma opinião quando repetem uma estrutura falada pelo outro interlocutor. Desse modo, observamos que, nos exemplos apresentados, temos uma atividade de heterorrepetições, em que o informante utiliza parte dos elementos ditos pelo documentador e constrói colaborativamente o texto, amalgamando ideias e linguagem.

Por fim, a função reforço foi a mais encontrada em nossa amostra de análise, com o percentual de 42\%. Marcuschi (2006) denomina esse aspecto funcional de intensificação, pois, como veremos nos exemplos a seguir, os informantes repetem expressões idênticas, objetivando intensificar o argumento. Vejamos:

(07) INF: O que eu mudaria de imediato... a lei do país... muito... muito... muito... muito... muito desorganizada essa lei do país (D.A.O, PCVC);

(08) DOC: Alguma coisa que você acha que... que num é agradável, que você mudaria assim, tem algo específico que você mudaria? Você não goste dentro da profissão. INF: Não. Não tem não. (A.S.A, PCVC);

(09) INF: Mas eu fiz um escândalo... mas eu fiz um escândalo tão grande... tão grande (A.I.R.M, PCVC);

(10) DOC: Continua viva até agora

INF: Continua viva até agora (F.S.L.B, PCVC).

Existem duas subcategorias básicas de reforço: a primeira, autoexpressiva, "articula as unidades mínimas de cada UD, através, principalmente, da repetição adverbial" (OLIVEIRA, 1998, p. 47), como podemos observar na ocorrência (07); já a segunda é característica da conversação, pois nela, por meio da heterorrepetição, "um dos interlocutores reelabora total ou parcialmente a fala do outro, tomando-a como sua" (OLIVEIRA, 1998, p. 47), como exemplificado no enunciado (10). Esse modelo de reforço é denominado, por Koch (1990), de sombreamento que, por vezes, é associado à sobreposição, considerando que a repetição produzida pelo falante proporciona a posse ou a retomada de turno, através da amplificação da matriz. 
Para uma melhor visualização da nossa análise percentual, vejamos a tabela a seguir:

Tabela 1: Análise percentual das categorias funcionais da repetição analisadas no Corpus

Português Culto de Vitória da Conquista

\begin{tabular}{l|l|l}
\hline Categoria & Quantidade de ocorrências & Percentual \\
\hline Enumeração & 94 & $29 \%$ \\
\hline Paralelização & 93 & $29 \%$ \\
\hline Reforço & 136 & $42 \%$ \\
\hline
\end{tabular}

Através da tabela, pudemos notar que com 136 ocorrências encontradas na nossa amostra de estudo, a função reforço alcançou os $42 \%$, dado esse que comprova a nossa hipótese inicial de que o reforço seria a estratégia mais produtiva entre as selecionadas. Tal resultado vai ao encontro da afirmação de Oliveira (1998), diante dos resultados de sua pesquisa: "a função reforço é, em números gerais, a mais recorrente" (OLIVEIRA, 1998, p. 46). Quanto à enumeração e à paralelização, encontramos 93 e 94 ocorrências respectivamente, desse modo, os dois aspectos alcançaram valor semelhante, 29\%, e mostraram-se produtivos também em nossos dados.

Por meio dessa breve análise, pudemos perceber como a repetição é de suma importância para a construção do texto falado. Ainda que os preceitos da modalidade escrita ordenam a não utilização dessa estratégia, tornando-a estigmatizada, ela não deixa de ser um recurso que contribui para a coesividade do processamento textual, manutenção dos tópicos e intensificação dos fatores semânticos e argumentativos, facilitando, assim, a interatividade entre os interlocutores.

Em suma, a repetição é regida pelo princípio de iconicidade e pela marcação expressiva, no sentido em que o informante, motivado pelas pressões de uso, vale-se de palavras, estruturas, sentidos que já existem na língua e que foram ditos em um processo de autorrepetição ou em um processo de heterorrepetição. Por fim, podemos notar como a repetição é a consequência da relação entre forma e função, sendo, assim, um processo que possibilita a organização da experiência humana, chegando ao âmbito textual por meio dos atos de fala e produzindo, cognitivamente, estruturas linguísticas dispostas em camadas hierárquicas.

\section{Para concluir}

A partir deste estudo inicial acerca da repetição na oralidade, atestamos todas as nossas hipóteses: (i) a repetição é uma estratégia altamente produtiva na oralidade, uma vez que todos os aspectos funcionais foram encontrados no Corpus PCVC; (ii) cada um dos itens, quando repetidos, tornam-se "peças-chave" necessárias no processamento textual-discursivo e na comunicação entre os interlocutores; (iii) a repetição, motivada em uma dimensão discursiva (iconicidade), demonstra uma relevante expressividade, pois o falante se vale de organizar, cognitivamente, construções que revelam o modo como interpreta a realidade que está a sua volta; e, por fim, (iv) o reforço é a função mais recorrente entre as funções selecionadas - enumeração, paralelização e reforço. Ademais, constatamos que a repetição é um recurso utilizado para melhorar a compreensão e a interação direta e ativa entre os interlocutores. 


\section{REFERÊNCIAS}

AREAS, E. K.; MARTELOTTA, M. E. A visão funcionalista da linguagem no século XX. In: MARTElOTTA, M. E.; OlIVEIRA, M. R. de; CUNHA, M. A. F. da. Lingüística funcional: teoria e prática. Rio de Janeiro: DP\&A, 2003. p. 18-55.

CASTILHO, A. T. de. Um ponto de vista funcional sobre a predicação. In: ALFA: Revista de Linguística. São Paulo: UNESP, v.38, p.75-96, 1994.

p. 232-233.

Gramática do Português Brasileiro. 1. ed. 3. reimp. São Paulo: Contexto, 2014.

CUNHA, A. F. da. Funcionalismo. In: MARTELOTTA, M. E. et al. (orgs.). Manual de Linguística. São Paulo: Contexto, 2015. p. 158-176.

DUBOIS, S.; VOTRE, S. Análise modular e princípios subjacentes do funcionalismo linguístico: à procura da essência da linguagem. Impresso, 1994.

GIVÓN, T. Topic continuity in discourse: quantitative cross-language studies. Amsterdam: John Benjamins, 1983. p.113-141.

Functionalism and grammar. Amsterdã: John Benjamins, 1995. p. 93-110.

KOCH, I. G. V. Aspectos do processamento do fluxo de informação do discurso oral dialogado. In: CASTILHO, A. T. de (org.). Gramática do Português falado. Campinas: Editora da UNICAMP, 1990. p. 143-184.

LIMA-HERNANDES, M. C. A evolução da gramática e o aporte funcionalista bases teóricas. In: _. Indivíduo, sociedade e língua: Cara, tipo assim, fala sério. São Paulo: Editora da Universidade de São Paulo: Fapesp, 2011. p. 21-22.

MARCUSCHI, L. A. Repetição. In: JUBRAN, C. C. A. S.; KOCH, I. G. V. (orgs.). Gramática do português culto falado no Brasil: construção do texto falado. v.1. Campinas: Editora da UNICAMP, 2006. p. 219-254.

A Repetição na língua falada como estratégia de formulação textual. In: KOCH, I. G. V. (org.). Gramática do Português Falado. 2. ed. Campinas: Editora da UNICAMP, 2002. p. 95-129.

NEVES, M. H. de M. A gramática funcional. São Paulo: Martins: Fontes, 1997. p. 99142.

A gramática passada a limpo: conceitos, análises e parâmetros. São Paulo: Parábola Editorial, 2012. p. 48-80.

OLIVEIRA, M. R. de. Gramaticalização na repetição. In: MARTELOTA, M. E.; VOTRE, S. J.; CEZÁRIO, M. M. Gramaticalização no português do Brasil: uma abordagem funcional. Rio de Janeiro. Tempo Brasileiro, 1996. p. 147-165.

Repetição em diálogos: análise funcional da conversão. Niterói: EDUFF, 1998. p. $15-175$.

SILVA, J. A. A.; SOUSA, V. V. Português culto de Vitória da Conquista. 2013. Projeto do Grupo de Pesquisa em Linguística Histórica e Grupo de Pesquisa em Sociofuncionalismo - UESB, 2013. 
SILVA, V. L. P. Desfazendo um mito: a repetição na escrita e suas funções. In: RONCARATI, C.; ABRAÇADO, J. (org.). Português Brasileiro II: contato linguístico, heterogeneidade e história. Niterói: EDUFF, 2008. p. 334-344.

TAVARES, M. A. A Gramaticalização de E, Aí, Daí e Então: estratificação/variação e mudança no domínio funcional da sequenciação retroativo-propulsora de informações um estudo sociofuncionalista. 2003. 307 f. Tese (Doutorado em Linguística) Universidade Federal de Santa Catarina, Florianópolis.

Recebido em: 26/09/2015

Aprovado em: 15/02/2016 